\title{
Improvement of the Surface Activity and the Solubility for Some Synthesized Polyaniline Surfactants
}

\author{
S.M. Sayyah", E.M.S. Azzam*, A.B. Khalil and S.M. \\ Mohamed \\ Chemistry Department, Faculty of Science, Beni Suef \\ University 62514 Beni Suef and ${ }^{*}$ Egyptian Petroleum Research \\ Institute, 11727 Elzhoor, Nasr City, Cairo, Egypt.
}

\begin{abstract}
COME monomeric surfactants namely, 3(6- sodium sulfonate Shexacyloxy) aniline $\left(\mathrm{MC}_{6}\right)$, 3(10- sodium sulfonate decyloxy) aniline $\left(\mathrm{MC}_{10}\right)$ and 3(12- sodium sulfonate dodecyloxy) aniline $\left(\mathrm{MC}_{12}\right)$ and their analogous polymers were synthesized. Different techniques were used to characterize the synthesized monomeric and their analogous polymeric surfactants such as ultraviolet-visible (UV), thermal gravimetric analysis (TGA), X-ray and scanning electron microscopy (SEM) techniques. The surface tension technique was used to investigate the surface properties of these surfactants at different temperatures. The critical micelle concentration (CMC) results showed the improvement in the solubility of the synthesized polymeric surfactants according to the effect of the hydrophobic and hydrophilic moieties in their chemical structure. The surface parameters showed the ability of monomeric and their analogous polymeric surfactants for adsorption at the air / water interfaces and decreased the surface tension. The thermodynamic parameters revealed that the micellization process is spontaneous for all investigated surfactants as a result of the improvement of the solubility of these surfactants.
\end{abstract}

Keywords: Monomeric and polymeric aniline surfactants, Solubility, Surface properties and Thermodynamic parameters.

Polyaniline as an electrically conductive polymer has attracted considerable attention. Because of its excellent environmental stability in the electroconducting form, it has many potential applications; unique electrical and optical properties $^{(1)}$. Conducting polymers are salts of inorganic acceptors and organic donors consisting of large, cyclically conjugated electron systems ${ }^{(2)}$. A common feature of conducting polymer is conjugation of $\pi$-electrons extending over the length of the polymer backbone. The applications of polyaniline have been limited due to its poor solubility ${ }^{(3)}$. Several studies have been done in order to improve the solubility of polyaniline, such as the polymerization of aniline derivatives. The most studied aniline derivatives are alkyl ${ }^{(4)}$, alkyloxy ${ }^{(5-6)}$,

"To whom corresponding should be addressed.

E-mail: smsayyah@hotmail.com 
hydroxyl $^{(7)}$, chloroaniline with substitution in the ortho and meta position ${ }^{(8-10)}$. Water soluble polymers are used as surface active agents due to amphipathic molecules which consist of a non-polar hydrophobic portion, usually a straight or branched hydrocarbon chain containing 8-18 carbon atoms, attached to a polar or ionic portion (hydrophilic) ${ }^{(11)}$. Adsorption of surfactant molecules at the interface, lowers the surface tension and highers the surfactant adsorption ${ }^{(12)}$. Surfactants find application in almost every chemical industry, including detergents, paints, dyestuffs, pharmaceuticals, agrochemicals, fibers and plastics and corrosion inhibitors.

In the present studies we intend to improve the solubility of polyanilines, prepared by oxidative chemical polymerization of the synthesized 3-alkyloxy aniline sodium sulfonate monomeric surfactants. The obtained polymer samples were characterized using ultraviolet-visible (UV), thermal gravimetric analysis (TGA), X-ray and scanning electron microscopy (SEM) techniques. The surface and thermodynamic properties of micellization and adsorption of the synthesized monomeric and their analogous polymeric surfactants in addition to the effect of hydrophobic and hydrophilic on the solubility of the synthesized monomeric and their analogous polymeric surfactants were also investigated.

\section{Experimental}

Synthesis of monomeric 3-alkyloxy anilines sodium sulfonate

3-(6-Bromohexayloxy) aniline, 3-(10-bromodecyloxy) aniline and 3-(12bromododecyloxy) aniline were prepared by the reaction of $(1: 1) 3$-aminophenol with 1,6- dibromohexane, 1,10- dibromodecane and 1,12- dibromododecane, respectively, in the presence of sodium ethoxide .

3-(6-Bromohexayloxy) aniline, 3-(10-bromodecane) aniline and 3-(12bromododecane) aniline were reacted with sodium sulfite to produce 3(6sodium sulfonate hexacyloxy) aniline $\left(\mathrm{MC}_{6}\right), 3(10$ - sodium sulfonate decyloxy) aniline $\left(\mathrm{MC}_{10}\right)$ and 3(12- sodium sulfonate dodecyloxy) aniline $\left(\mathrm{MC}_{12}\right)$.

\section{Synthesis of polymeric surfactant}

The amount of monomers $(0.075 \mathrm{~mol})$ of 3(6-sodium sulfonate hexacyloxy) aniline, 3(10- sodium sulfonate decyloxy) aniline and 3(12- sodium sulfonate dodecyloxy) aniline were dissolved in $25 \mathrm{ml}$ of $2.0 \mathrm{M} \mathrm{HCl}$ solutions in a well stoppered conical flasks of $250 \mathrm{ml}$ capacity followed by the addition of the required amounts of potassium per- sulfate $0.15 \mathrm{M}$ dissolved in $25 \mathrm{ml}$ of $2.0 \mathrm{M}$ $\mathrm{HCl}$ solutions to the reaction mixture under nitrogen atmosphere. The orders of addition of substances were kept constant in all the performed experiments. The stoppered conical flasks were then placed in automatically controlled thermostat at $25^{\circ} \mathrm{C}$. The flasks were shaken $(50$ shakings $/ 10 \mathrm{~s} / 15 \mathrm{~min}$ ) for $1 \mathrm{hr}$ by using an automatic shaker. The flasks were left for $72 \mathrm{hr}$ at room temperature to continue the reaction and then filtered using a Buchner funnels. Then the solids were 
washed with the distilled water, and finally dried under vacuum at room temperature until constant weight.

Elemental and spectroscopic analysis

The elemental analyses of the prepared monomeric and polymeric surfactants were measured using oxygen flask combustion and a dosimat E415 titirator (Switzerland) .

The infrared spectroscopic analyses of the prepared monomeric and polymeric surfactants were carried out in the Micro Analytical Laboratory at Cairo University by using a Shimadzu FTIR-430 Jasco Spectrophotometer and $\mathrm{KBr}$ disc techniques.

The ultraviolet-visible absorption spectra of the prepared monomeric and polymeric surfactants were measured using Shimadzu UV spectrophotometer (M $160 \mathrm{PC}$ ) at room temperature in the range $200-400 \mathrm{~nm}$ using dimethylformamide as a solvent and reference.

Thermal gravimetric analysis (TGA), scanning electron microscopy (SEM )and $X$-ray spectroscopy

Thermal gravimetric analysis (TGA) of the polymer samples was performed using a Shimadzu DT-30 thermal analyzer. The weight loss was measured from ambient temperature up to $600{ }^{\circ} \mathrm{C}$ at rate of $20{ }^{\circ} \mathrm{C}$ per minute to determine the rate of degradation of the polymers.

Scanning electron microscopy and X-ray diffractometer (philip1976.model1390) was operated for the polymer samples under the following conditions which were kept constant for all of the analysis processes $\mathrm{Cu}$ X-ray tube, scan speed = $8 / \mathrm{min}$ current $=30 \mathrm{~mA}$, voltage $=40 \mathrm{kv}$ and preset time $=10 \mathrm{~s}$.

Critical micelle concentration and surface tension

Critical micelle concentration and surface tension were measured by using K100 Tensiometer (Kruss Type, Germany) for the hydrochloric form of synthesized monomeric and polymeric surfactants using different concentrations.

\section{Materials}

3-Aminophenol provided by Aldrich Chemical Co. Sodium sulfite used in the synthetic process was obtained from Merck Chemical Co., (Germany). Concentrated hydrochloric acid was chemically pure grade products provided by Prolabo-Chemical Co., (U.K.). Doubly distilled water was used to prepare all solutions. Potassium persulfate and 1,6- dibromohexane, 1,10- dibromodecane and 1, 12- dibromododecane were obtained from Aldrich Chemical Co., England. 


\section{Results and Discussion}

The elemental analysis of the prepared monomeric surfactants and their polymers

The elemental analysis of the prepared monomeric surfactants and their polymers are summarized in Table 1 . The data show that, there is a good agreement with the calculated one for the suggested structures present in Scheme 1 .

TABLE 1. Elemental analysis of the prepared monomeric surfactants and their analogs polymers.

\begin{tabular}{|c|c|c|c|c|c|c|c|c|c|c|}
\hline \multirow{2}{*}{ Name } & \multicolumn{2}{|c|}{ C \% } & \multicolumn{2}{c|}{ H \% } & \multicolumn{2}{c|}{ Cl \% } & \multicolumn{2}{c|}{ S \% } & \multicolumn{2}{c|}{ N \% } \\
\cline { 2 - 10 } & Cal. & Found & Cal. & Found & Cal. & Found & Cal. & Found & Cal. & Found \\
\hline $\mathrm{MC}_{6}$ & 48.81 & 48.12 & 6.10 & 5.99 & - & - & 10.85 & 10.65 & 4.75 & 4.58 \\
$\mathrm{PC}_{6}$ & 46.27 & 46.92 & 6.72 & 6.54 & 5.70 & 5.75 & 10.28 & 10.36 & 4.50 & 4.53 \\
$\mathrm{MC}_{10}$ & 65.08 & 64.12 & 8.81 & 8.73 & - & - & 10.85 & 10.73 & 4.75 & 4.61 \\
$\mathrm{PC}_{10}$ & 52.28 & 52.14 & 7.49 & 7.54 & 4.83 & 4.68 & 8.71 & 8.75 & 3.81 & 3.72 \\
$\mathrm{MC}_{12}$ & 73.22 & 72.93 & 10.17 & 10.02 & - & - & 10.85 & 10.63 & 4.75 & 7.66 \\
$\mathrm{PC}_{12}$ & 54.65 & 55.37 & 7.97 & 7.69 & 4.44 & 4.51 & 8.10 & 8.04 & 3.54 & 3.52 \\
\hline
\end{tabular}

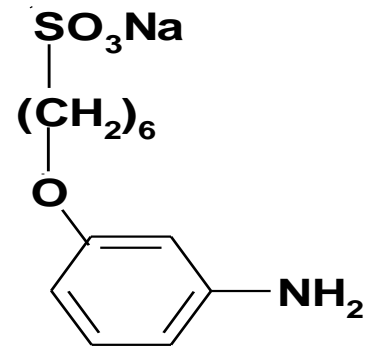

3(6- Sodiumsulfonate hexayloxy) aniline $\left(\mathrm{MC}_{6}\right)$.

Egypt. J. Chem. 55, No. 6 (2012) 


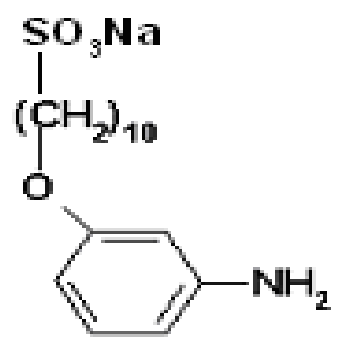

3(10- Sodiumsulfonate decyloxy) aniline $\left(\mathrm{MC}_{10}\right)$.

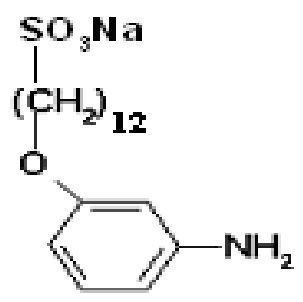

3(12- Sodiumsulfonate dodecyloxy) aniline $\left(\mathrm{MC}_{12}\right)$.

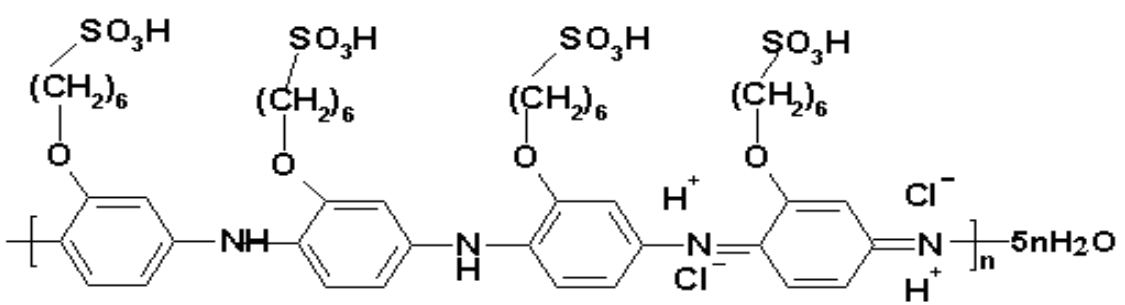

Poly 3-(hexayloxy sulfonic acid) aniline ( $\left.\mathbf{P C}_{6}\right)$.

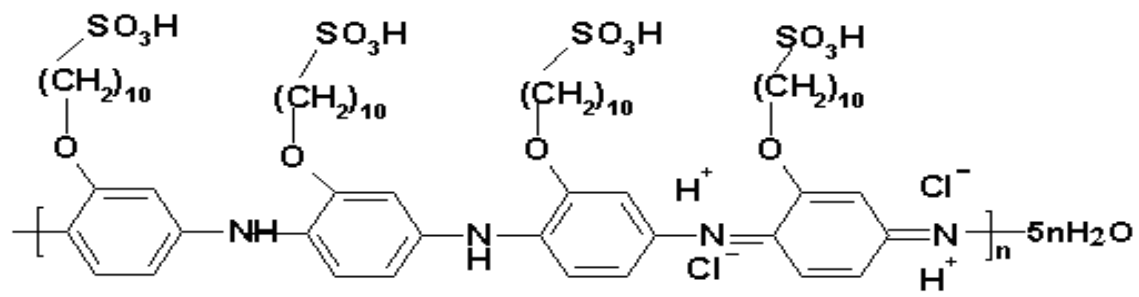

Poly 3-(decyloxy sulfonic acid) aniline $\left(\mathbf{P C}_{10}\right)$. 


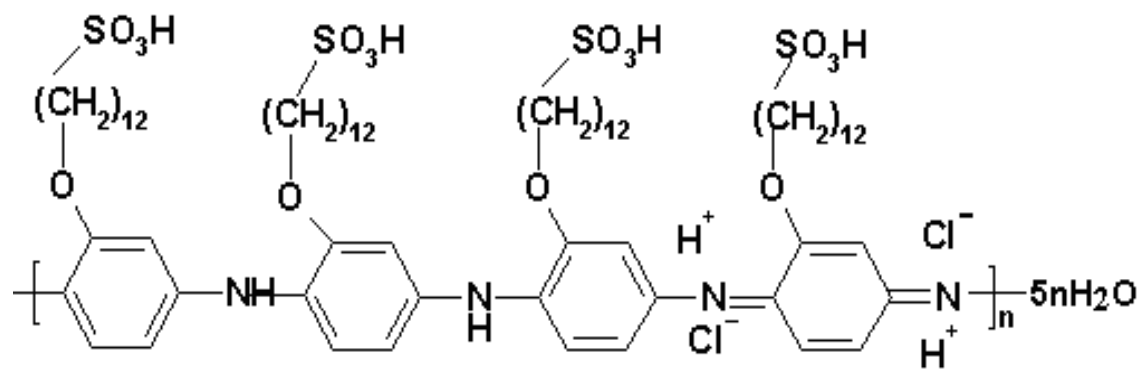

Poly 3-(dodecyloxy sulfonic acid) aniline $\left(\mathrm{PC}_{12}\right)$.

Scheme 1. Structure of monomeric surfactants and their polymers.

The infrared spectroscopic analysis of the prepared monomeric surfactants and their polymers

(i) The IR spectra of 3-(6-sodiumsulfonate hexayloxy) aniline and its polymer

The IR spectra of the prepared monomeric surfactant 3-(6-sodiumsulfonate hexayloxy) aniline $\left(\mathrm{MC}_{6}\right)$ and its polymer $\left(\mathrm{PC}_{6}\right)$ are represented in Fig. 1. The strong absorption band appearing at $626 \mathrm{~cm}^{-1}$ which could be attributed to out of plane deformation of $\mathrm{CH}$ for 1,3-disubstituted benzene ring in case of monomer but disappears in case of polymer. The medium absorption band appearing at 755 $\mathrm{cm}^{-1}$ which may be due to the rocking deformation of methylene group in aliphatic chain in case of monomer, appears at $750 \mathrm{~cm}^{-1}$ with slight shift in case of polymer. The sharp absorption band appearing at $972 \mathrm{~cm}^{-1}$ which could be attributed to symmetric stretching vibration of S-O or C-N group in case of monomer, appears at $917 \mathrm{~cm}^{-1}$ as a medium band with slight shift in case of polymer. The medium absorption band appearing at $1545 \mathrm{~cm}^{-1}$ which could be attributed to symmetric stretching vibration of $\mathrm{C}=\mathrm{C}$ in quinoide structure in benzene ring in case of polymer, disappears in case of monomer. The broad absorption band appearing at $1624 \mathrm{~cm}^{-1}$ which could be attributed to symmetric stretching vibration of $\mathrm{C}=\mathrm{C}$ in case of monomer, appears as splited band at 1616 and $1639 \mathrm{~cm}^{-1}$ in case of polymer. The broad absorption band appearing at $3235 \mathrm{~cm}^{-1}$ which may be due to symmetric stretching vibration for hydrogen bonded $\mathrm{OH}$ group of sulphonic group in case of polymer, disappears in case of monomer. The medium absorption band appearing at $3414 \mathrm{~cm}^{-1}$ which may be attributed to symmetric stretching vibration of $\mathrm{NH}$ group in case of monomer, disappears in case of polymer. 


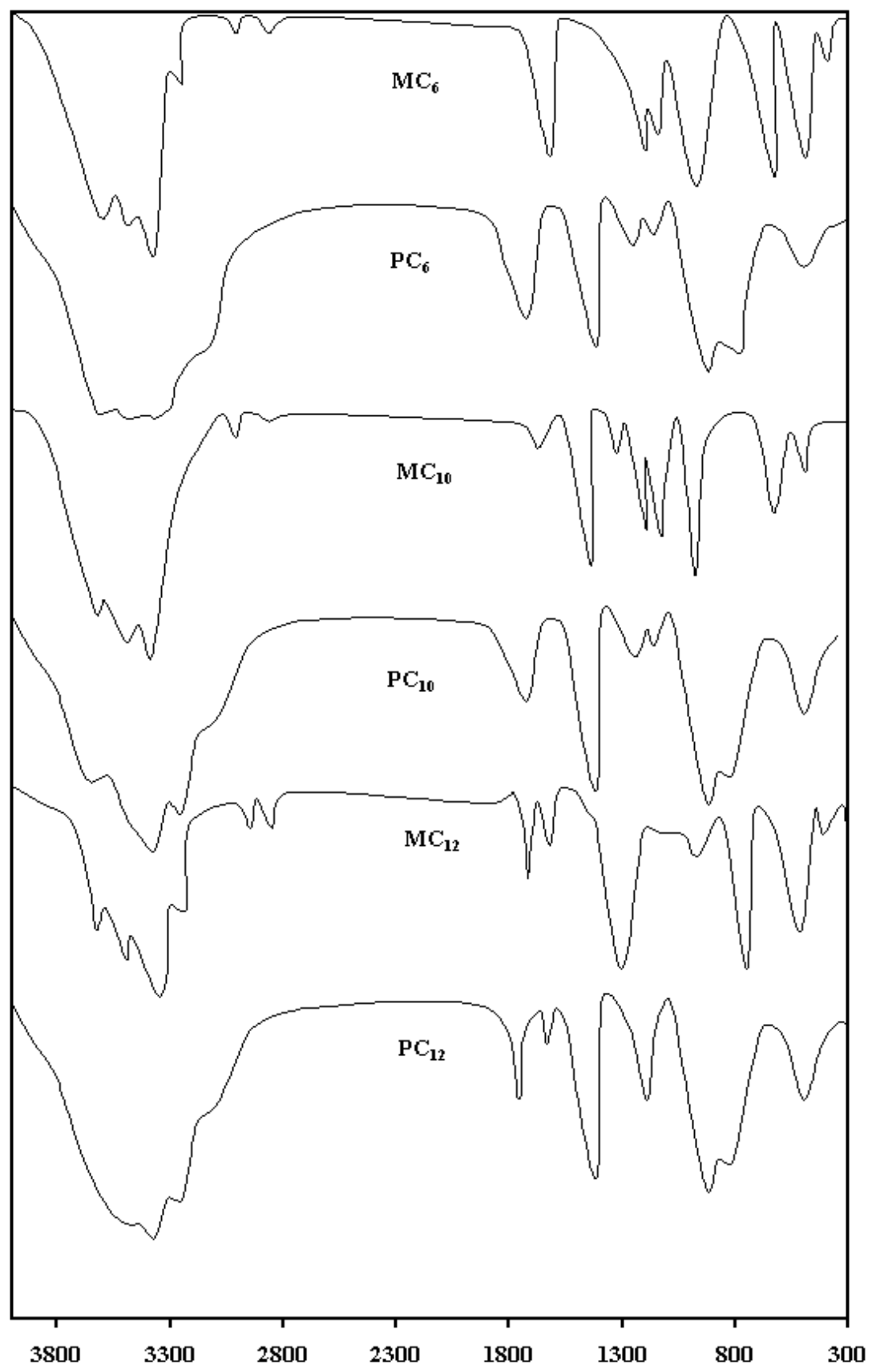

Fig.1. Infrared spectrum of the prepared monomeric surfactants and its polymer .

Egypt. J. Chem. 55, No. 6 (2012) 
(ii) The IR spectra of 3(10- sodiumsulfonate decyloxy) aniline and its polymer

The IR spectra of the prepared monomeric surfactant 3(10- sodiumsulfonate decyloxy) aniline $\left(\mathrm{MC}_{10}\right)$ and its polymer $\left(\mathrm{PC}_{10}\right)$ are represented in Fig. 1. The shoulder absorption band appearing at $630 \mathrm{~cm}^{-1}$ which could be attributed to out of plane deformation of $\mathrm{CH}$ for 1,3-disubstituted benzene ring in case of monomer disappears in case of polymer. The sharp absorption band appearing at $751 \mathrm{~cm}^{-1}$ due to the rocking deformation of methylene group in aliphatic chain in case of monomer appears as a broad band at $755 \mathrm{~cm}^{-1}$ with slight shift in case of polymer. The medium absorption band appearing at $820 \mathrm{~cm}^{-1}$ which could be attributed to out of plane deformation of $\mathrm{CH}$ group in 1,3,4-trisubstituted benzene ring in case of polymer, disappears in case monomer. The medium absorption band appearing at $918 \mathrm{~cm}^{-1}$ which could be attributed to symmetric stretching vibration of S-O or C-N group in case of monomer, appears as sharp band at $974 \mathrm{~cm}^{-1}$ with slight shift in case of polymer. The medium absorption band appearing at $1565 \mathrm{~cm}^{-1}$ which could be attributed to symmetric stretching vibration of $\mathrm{C}=\mathrm{C}$ in quinoide structure in benzene ring, disappears in case of monomer. The medium absorption band appearing at $2928 \mathrm{~cm}^{-1}$ which could be attributed to asymmetric stretching vibration of $\mathrm{CH}$ group in aliphatic chain in case of monomer, appears at $2930 \mathrm{~cm}^{-1}$ in case of polymer. The shoulder absorption band appearing at $3147 \mathrm{~cm}^{-1}$ which could be attributed to symmetric stretching vibration of hydrogen bonded $\mathrm{OH}$ group in case of polymer, disappears in case of monomer. The broad absorption band appearing at 3447 $\mathrm{cm}^{-1}$ which could be attributed to asymmetric stretching vibration for $\mathrm{NH}$ group in case of monomer, appears as medium absorption band at $3470 \mathrm{~cm}^{-1}$ in case of polymer.

(iii) The IR spectra of 3(12-sodiumsulfonate dodecyloxy) aniline and its polymer

The IR spectra of the prepared organic surfactant 3(12- sodiumsulfonate dodecyloxy) aniline and its polymer are represented in Fig. 1. The sharp absorption band appearing at $753 \mathrm{~cm}^{-1}$ which could be due to the rocking deformation of methylene group in aliphatic chain in case of polymer appears as a broad band at $758 \mathrm{~cm}^{-1}$ with slight shift in case of polymer. The medium absorption band at $818 \mathrm{~cm}^{-1}$ which may be attributed to out of plane deformation of $\mathrm{CH}$ group in 1,3,4-trisubstituted benzene ring in case of polymer disappears in case monomer. The medium absorption band appearing at $1566 \mathrm{~cm}^{-1}$ which could be attributed to symmetric stretching vibration of $\mathrm{C}=\mathrm{C}$ in quinoide structure in benzene ring, disappears in case of monomer. The weak absorption band appearing at $2839 \mathrm{~cm}^{-1}$ which could be attributed to symmetric stretching vibration for $\mathrm{CH}$ aliphatic in case of monomer, appears at $2840 \mathrm{~cm}^{-1}$ in case of polymer. The broad absorption band appearing at $3478 \mathrm{~cm}^{-1}$ in case of monomer which could be attributed to asymmetric stretching vibration of $\mathrm{NH}$ group, appears as broad band at $3400 \mathrm{~cm}^{-1}$ in case of polymer.

Egypt. J. Chem. 55, No. 6 (2012) 
The UV-visible spectroscopic studies of the prepared monomeric surfactants and their polymers

(A) The UV-visible spectra of the prepared organic surfactant 3-(6sodiumsulfonate hexayloxy) aniline and its polymer are represented in Fig. 2; the spectra show the following absorption bands:

(1) In case of monomer, two absorption bands appear at $\lambda_{\max }=214$ and $227 \mathrm{~nm}$ which may be attributed to $\pi-\pi^{*}$ transition ( $E_{2}$-band) of the benzene ring and the $\beta$-band $\left(\mathrm{A}_{1 \mathrm{~g}}-\mathrm{B}_{2 \mathrm{u}}\right)$.

(2) In case of polymer, two absorption bands appear at $\lambda_{\max }=211$ and $225 \mathrm{~nm}$ which may be attributed to $\pi-\pi^{*}$ transition showing a bathochromic shift. Beside these two bands, broad absorption band appears in the visible region at $\lambda_{\max }=$ $352 \mathrm{~nm}$ which may be due to the high conjugation of the aromatic polymeric chain.

(B) The UV spectra of the prepared organic surfactant 3(10- sodiumsulfonate decyloxy) aniline and its polymer are represented in Fig. 2, The spectra show the following absorption bands:

(1) In case of monomer, two absorption bands appear at $\lambda_{\max }=206$ and $210 \mathrm{~nm}$ which may be attributed to $\pi-\pi^{*}$ for transition ( $E_{2}$-band) of the benzene ring and the $\beta$-band $\pi-\pi^{*}$ transition $\left(\mathrm{A}_{1 \mathrm{~g}}-\mathrm{B}_{2 \mathrm{u}}\right)$.

(2) In case of polymer, two absorption bands appear at higher wavelength at $\lambda_{\max }=211$ and $253 \mathrm{~nm}$ which may be attributed to $\pi-\pi^{*}$ transition showing a bathochromic shift. Beside these two bands an absorption band appears in the visible region at $\lambda_{\max }=348 \mathrm{~nm}$ which may be due to the high conjugation of the aromatic polymeric chain.

(C) The UV spectra of the prepared organic surfactant 3(12-sodiumsulfonate dodecyloxy) aniline and its polymer are represented in Fig. 2, The spectra show the following characteristic absorption bands:

(1) In case of monomer, two absorption bands appear at $\lambda_{\max }=207$ and $211 \mathrm{~nm}$ which may be attributed to $\pi-\pi^{*}$ transition ( $E_{2}$-band) of the benzene ring and the $\beta$-band for $\pi-\pi^{*}$ transition $\left(\mathrm{A}_{1 \mathrm{~g}}-\mathrm{B}_{2 \mathrm{u}}\right)$.

(2) In case of polymer, two absorption bands appear at higher wavelength at $\lambda_{\max }=210$ and $240 \mathrm{~nm}$ which may be attributed to $\pi-\pi^{*}$ transition showing a bathochromic shift. Beside these two bands an absorption band appears in the visible region at $\lambda_{\max }=344 \mathrm{~nm}$ which may be due to the high conjugation of the aromatic polymeric chain.

Thermal gravimetric analysis (TGA) and differential thermal analysis (DTA)

Thermogravimetric analysis (TGA) for the three prepared polymeric surfactants have been investigated and the TGA-data are summarized in Table 2. The thermal degradation steps are summarized as follows: 

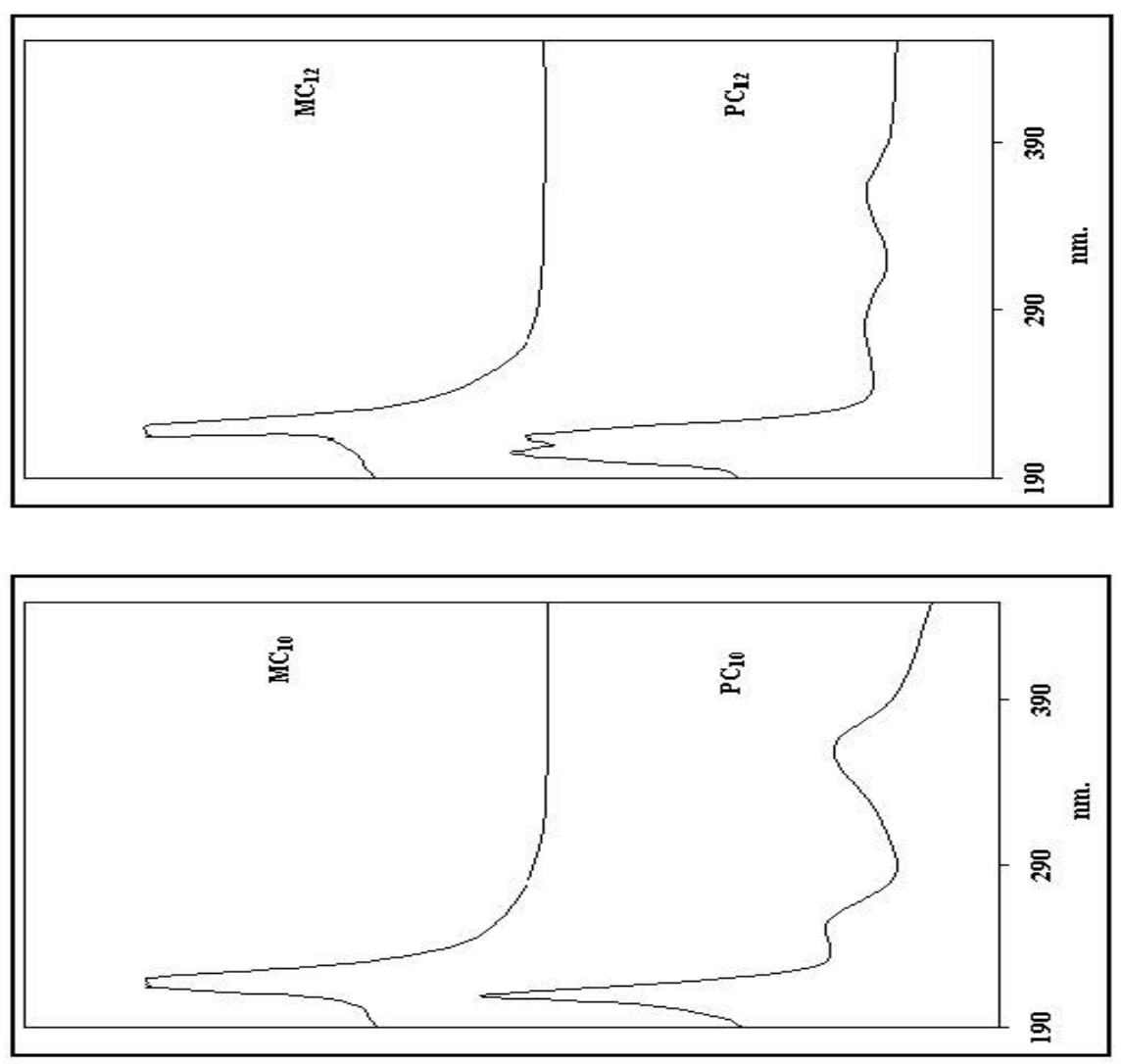

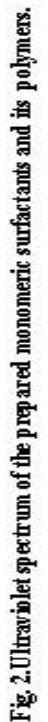

Egypt. J. Chem. 55, No. 6 (2012) 
TABLE 2. Thermogravimetric data of the prepared polymeric surfactants.

\begin{tabular}{|c|c|c|c|c|}
\hline \multirow{2}{*}{ Name } & \multirow{2}{*}{$\begin{array}{l}\text { Temperature } \\
\text { range }{ }^{0} \mathrm{C}\end{array}$} & \multicolumn{2}{|c|}{ Weight $\operatorname{loss}(\%)$} & \multirow{2}{*}{$\begin{array}{c}\text { The removed } \\
\text { molecule }\end{array}$} \\
\hline & & Calculated & Found & \\
\hline \multirow{5}{*}{$\mathrm{PC}_{6}$} & $25-126.5$ & 7.22 & 7.01 & $5 \mathrm{H} 2 \mathrm{O}$ \\
\hline & $126.5-177.4$ & 5.86 & 5.71 & $2 \mathrm{HCl}$ \\
\hline & $177.4-280.82$ & 14.53 & 13.48 & $\mathrm{O}-\left(\mathrm{CH}_{2}\right)_{6} \mathrm{SO}_{3} \mathrm{H}$ \\
\hline & $280.82-600.00$ & 14.53 & 13.35 & $\mathrm{O}-\left(\mathrm{CH}_{2}\right)_{6} \mathrm{SO}_{3} \mathrm{H}$ \\
\hline & $\begin{array}{c}\text { remaining weight } \\
(\%) \text { above } \\
600.00\end{array}$ & $\ldots \ldots$ & 60.55 & $\ldots \ldots \ldots$ \\
\hline \multirow{5}{*}{$\mathrm{PC}_{10}$} & $25-124.65$ & 6.15 & 6.23 & $5 \mathrm{H} 2 \mathrm{O}$ \\
\hline & $124.65-172.40$ & 4.96 & 4.82 & $2 \mathrm{HCl}$ \\
\hline & $172.40-308.10$ & 32.26 & 32.09 & $2 \mathrm{O}-\left(\mathrm{CH}_{2}\right)_{10} \mathrm{SO}_{3} \mathrm{H}$ \\
\hline & $308.10-600.00$ & 16.13 & 16.3 & $\mathrm{O}-\left(\mathrm{CH}_{2}\right)_{10} \mathrm{SO}_{3} \mathrm{H}$ \\
\hline & $\begin{array}{c}\text { remaining weight } \\
(\%) \text { above } \\
600.00\end{array}$ & $\cdots \cdots$ & 40.56 & $\ldots \ldots \ldots$ \\
\hline \multirow{5}{*}{$\mathrm{PC}_{12}$} & $25-105.2$ & 5.69 & 5.43 & $5 \mathrm{H} 2 \mathrm{O}$ \\
\hline & $124.65-172.40$ & 4.61 & 4.26 & $2 \mathrm{HCl}$ \\
\hline & $172.40-308.10$ & 16.76 & 16.04 & $\begin{array}{c}\mathrm{O}-\left(\mathrm{CH}_{2}\right)_{12} \mathrm{SO}_{3} \mathrm{H} \\
\text { and } \mathrm{SO}_{3} \mathrm{H}\end{array}$ \\
\hline & $308.10-600.00$ & 10.24 & 9.63 & $2 \mathrm{SO}_{3} \mathrm{H}$ \\
\hline & $\begin{array}{c}\text { remaining weight } \\
(\%) \text { above } \\
600.00\end{array}$ & $\ldots \ldots$ & 64.65 & $\ldots$ \\
\hline
\end{tabular}

(A) For poly 3-(hexayloxy sulfonic acid) aniline $\left(P C_{6}\right)$

(1) The first stage : includes the loss of five molecules of water in the temperature range between $25-126.5^{\circ} \mathrm{C}$. The weight loss of this step was found to be $7.01 \%$ which is in a good agreement with the calculated one $(7.22 \%)$. 
(2) The second stage : in the temperature range between $126.5-177.4{ }^{\circ} \mathrm{C}$, the weight loss was found to be $5.71 \%$, which could be attributed to the loss of $2 \mathrm{HCl}$. The calculated weight loss is in good agreement with the found one $(5.86 \%)$.

(3) The third stage : in the temperature range between $177.4-280.82^{\circ} \mathrm{C}$, the weight loss was found to be $13.48 \%$, which is attributed to the loss of one molecule of $\mathrm{O}-\left(\mathrm{CH}_{2}\right)_{6} \mathrm{SO}_{3} \mathrm{H}$. The calculated weight loss of this stage is equal to $14.53 \%$.

(4) The fourth stage : in the temperature range between $280.82-600^{\circ} \mathrm{C}$, the weight loss was found to be $13.35 \%$, which is attributed to the loss of one molecule of $\mathrm{O}-\left(\mathrm{CH}_{2}\right)_{6} \mathrm{SO}_{3} \mathrm{H}$. The calculated weight loss of this stage is equal to $14.53 \%$.

(5) The last stage : above $600^{\circ} \mathrm{C}$, the remained polymer molecule was found to be $60.55 \%$ including the metallic residue but the calculated one was found to be $57.83 \%$.

(B) Poly 3-(decyloxy sulfonic acid) aniline $\left(P C_{10}\right)$

(1) The first stage : includes the loss of five molecules of water in the temperature range between $25-124.65{ }^{\circ} \mathrm{C}$. The weight loss of this step was found to be $6.23 \%$ which is in a good argument with the calculated one $(6.15 \%)$.

(2) The second stage : in the temperature range between $124.6-172.4^{\circ} \mathrm{C}$, the weight loss was found to be $4.82 \%$, which could be attributed to the loss of $2 \mathrm{HCl}$. The calculated weight loss in this case is equal to $4.96 \%$.

(3) The third stage : in the temperature range between $172.4-308.1^{\circ} \mathrm{C}$, the weight loss was found to be $32.09 \%$, which is attributed to the loss of two molecules of $\mathrm{O}-\left(\mathrm{CH}_{2}\right)_{10} \mathrm{SO}_{3} \mathrm{H}$. The calculated weight loss of this stage is equal to $32.26 \%$.

(4) The fourth stage : in the temperature range between $308.1-600^{\circ} \mathrm{C}$, the weight loss was found to be $16.3 \%$, which is attributed to the loss of one molecule of $\mathrm{O}-\left(\mathrm{CH}_{2}\right)_{10} \mathrm{SO}_{3} \mathrm{H}$. The calculated weight loss of this stage is equal to $16.133 \%$.

(5) The last stage : above $600^{\circ} \mathrm{C}$, the remained polymer molecule was found to be $40.56 \%$ including the metallic residue but the calculated one was found to be $40.50 \%$.

(C) Poly 3-(dodecyloxy sulfonic acid) aniline $\left(P C_{12}\right)$

(1)The first stage : includes the loss of five molecules of water in the temperature range between $25-105.2{ }^{\circ} \mathrm{C}$. The weight loss of this step was found to be $5.43 \%$ which is in a good agreement with the calculated one $(5.69 \%)$.

Egypt. J. Chem. 55, No. 6 (2012) 
(2)The second stage : in the temperature range between $105.2-172.6^{\circ} \mathrm{C}$, the weight loss was found to be $4.26 \%$ which could be attributed to the loss of $2 \mathrm{HCl}$. The calculated weight loss of this stage is equal to $4.61 \%$.

(3)The third stage : in the temperature range between $172.6-600^{\circ} \mathrm{C}$, the weight loss was found to be $16.04 \%$ which is attributed to the loss of one molecules of $\mathrm{O}-\left(\mathrm{CH}_{2}\right)_{12} \mathrm{SO}_{3} \mathrm{H}$ and $\mathrm{So}_{3} \mathrm{H}$ from another chain. The calculated weight loss of this stage is equal to $16.76 \%$.

(4)The fourth stage : in the temperature range between $336.5-600^{\circ} \mathrm{C}$, the weight loss was found to be $9.63 \%$, which is attributed to the loss of two $\mathrm{SO}_{3} \mathrm{H}$. The calculated weight loss of this stage is equal to $10.24 \%$.

(5)The last stage: above $600^{\circ} \mathrm{C}$, the remained polymer molecule was found to be $63.65 \%$ including the metallic residue but the calculated one was found to be $62.68 \%$.

\section{The X-ray diffraction analysis and electron microscopy}

The X-ray diffraction patterns of the three prepared polymers $\left(\mathrm{PC}_{6}, \mathrm{PC}_{10}\right.$ and $\mathrm{PC}_{12}$ ) are represented in Fig. 3. The figure shows that one of the prepared polymers $\left(\mathrm{PC}_{12}\right)$ is amorphous while the polymers $\mathrm{PC}_{6}$ and $\mathrm{PC}_{10}$ give peak at 2Theta equal to 19.835 degree with $\mathrm{d}$-spacing (4.4726) and the peak intensity in case of $\mathrm{PC}_{6}$ is higher than that of polymer $\mathrm{PC}_{10}$ has a small portion of crystallinity which are also confirmed by the electron microscopic picture represented in Fig. 4 . In case of $\left(\mathrm{PC}_{12}\right)$ there is no characteristic peak in the $\mathrm{X}$ ray diffraction patterns in the region of crystalline organic compounds indicating that the polymer is amorphous and from the electron microscopic picture it is clear that the amorphous grain particles of the polymers $\left(\mathrm{PC}_{12}\right)$ are ranged from spherical to elongated particles.

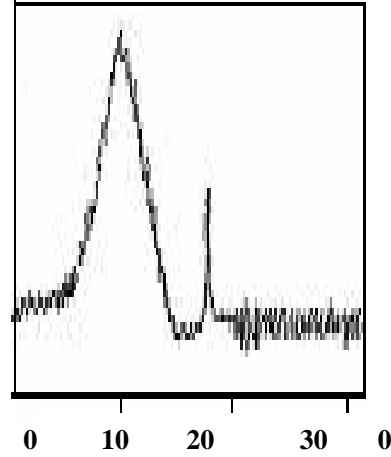

(A)

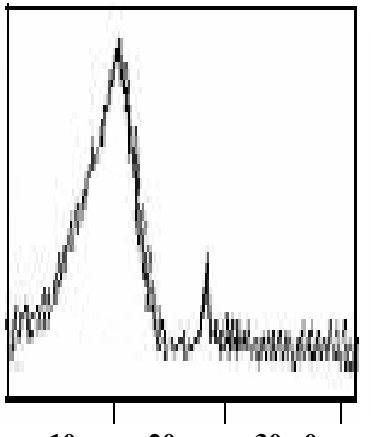

(B)

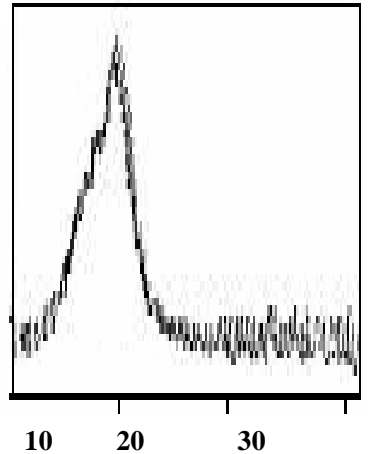

(C)

Fig. 3. X-ray of the prepared polymer samples $\mathrm{PC}_{6}(\mathrm{~A}), \mathrm{PC}_{10}(\mathrm{~B})$ and $\mathrm{PC}_{12}(\mathrm{C})$. 


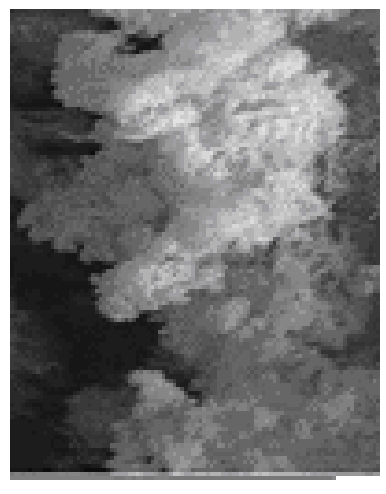

(A)

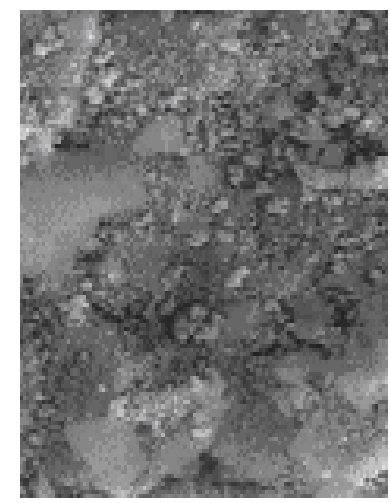

(B)

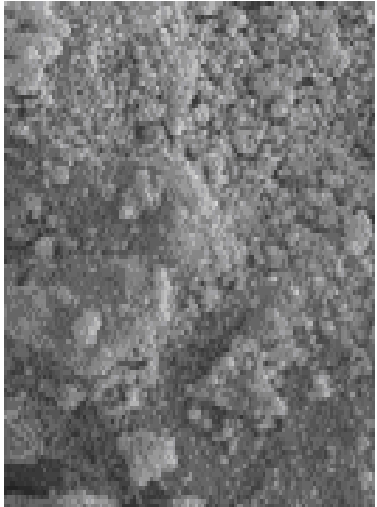

( C )

Fig. 4. Electron microscope picture of the prepared polymer samples $\mathbf{P C}_{6}(\mathrm{~A}), \mathbf{P C}_{10}$ (B) and $\mathrm{PC}_{12}(\mathrm{C})$.

\section{Critical micelle concentration and surface tension \\ Critical micelle concentration $(C M C)$ of the prepared surfactants}

The relations between the surface tension $(\gamma)$ and the different concentrations of the prepared monomeric and their polymeric surfactants at 25,35 and $50{ }^{\circ} \mathrm{C}$ are represented in Fig. 5. From Fig. 5, it is clear that the surface tension $(\gamma)$ decreases with the increasing of the prepared monomer and polymer concentrations which means also the increase of adsorption at air / water interface. The critical micelle concentration (CMC) of the prepared monomeric and their analogues polymeric surfactants was determined from the abrupt change in the slope of the corresponding plot of the surface tension $(\gamma)$ versus concentration. The CMC results in Table 3 show that the CMC values decrease as the alkyl chain moiety increases from $\mathrm{C}_{6}$ to $\mathrm{C}_{12}$ for all prepared surfactants. The lower values of CMC for the prepared surfactants indicate the ability of these surfactants to dissolve in water solution as a result of the presence of the hydrophilic $\mathrm{SO}_{3} \mathrm{Na}$ group terminal of the alkyl chain moiety. The presence of $\mathrm{SO}_{3} \mathrm{Na}$ group increases the solvation of $\mathrm{H}_{2} \mathrm{O}$ molecules surround it and increases the solubility of the surfactant molecule in solution. It was noticed that the CMC values of the prepared polymeric surfactants were lower than those of the prepared monomeric surfactants as shown in Table 3. These results may be due to that the polymeric surfactants have more hydrophilic and hydrophobic groups than those of the monomeric surfactants which enhance the solubility of the polymeric surfactants and lead to the decrease in CMC values.

Egypt. J. Chem. 55, No. 6 (2012) 


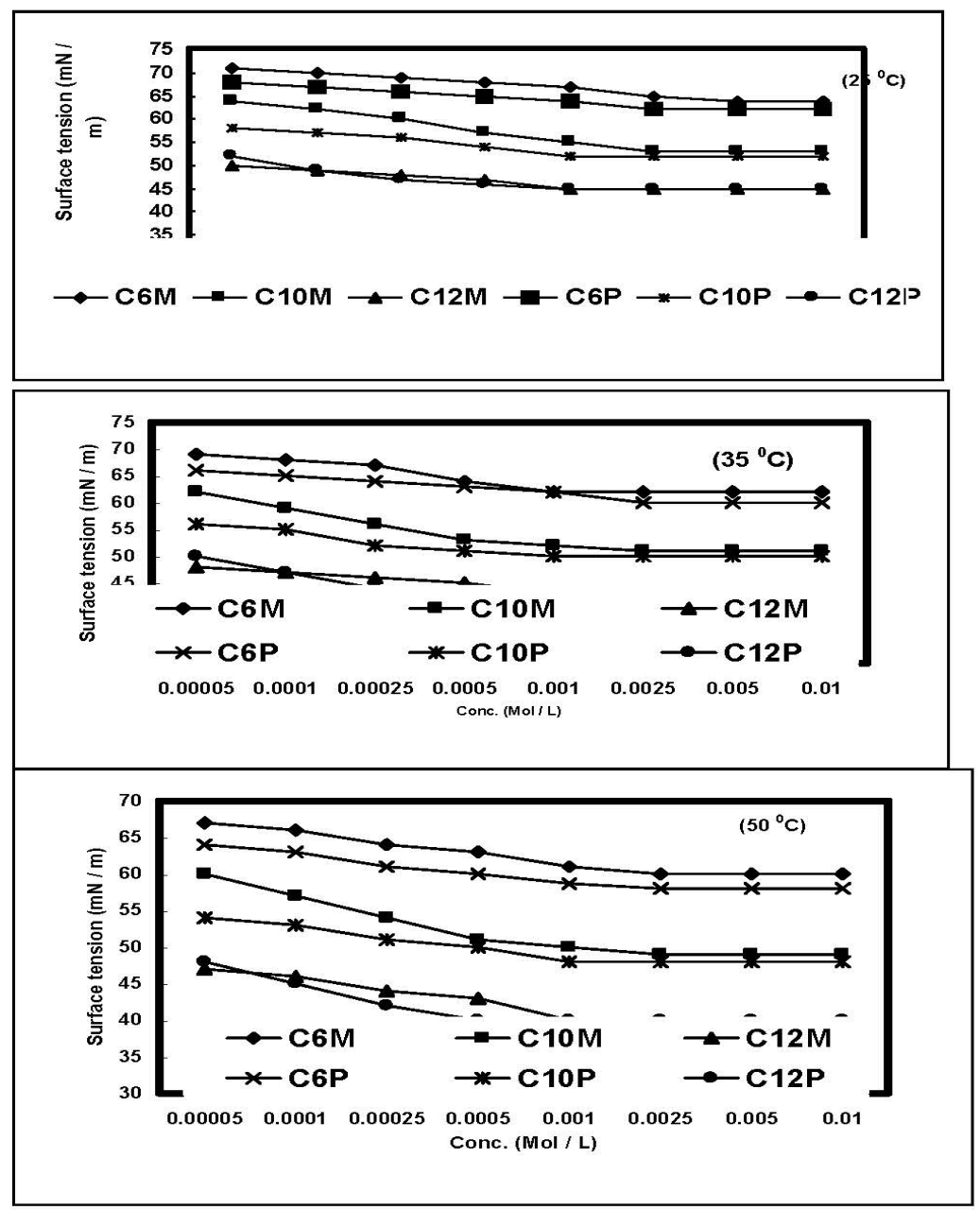

Fig. 5. The relations between the surface tension $(\gamma)$ and the different concent rations of the prepared monomeric and their analogues polymeric curfactants at 2535 and $50{ }^{\circ} \mathrm{C}$ 
TABLE 3. Critical micelle concentration (CMC), effectiveness $\Omega_{C M C}$, maximum surface excess $\left(r_{\max }\right)$ and minimum area $\left(A_{\min }\right)$ of monomeric surfactants $\left(\mathrm{MC}_{6}, \mathrm{MC}_{10}\right.$ and $\left.\mathrm{MC}_{12}\right)$ and their analogs polymeric surfactants.

\begin{tabular}{|c|c|c|c|c|c|}
\hline Surfactant & $\mathbf{T}\left({ }^{0} \mathrm{C}\right)$ & $\mathrm{CMC}(\mathrm{mol} / \mathrm{l})$ & $\begin{array}{l}r_{\max } \times 10^{-11} \\
\left(\mathrm{~mol} . \mathrm{cm}^{-2}\right)\end{array}$ & $\mathbf{A}_{\min \mathrm{nm}}{ }^{2}$ & $\boldsymbol{\Omega}_{\mathrm{CMC}}$ \\
\hline $\mathrm{MC}_{6}$ & \multirow{6}{*}{25} & 0.0005 & 4.85828 & 3.39548 & 7.80 \\
\hline $\mathrm{MC}_{10}$ & & 0.00025 & 8.46044 & 1.94980 & 17.80 \\
\hline $\mathrm{MC}_{12}$ & & 0.00025 & 2.82015 & 5.84941 & 25.80 \\
\hline $\mathrm{PC}_{6}$ & & 0.00025 & 2.82015 & 5.84941 & 8.80 \\
\hline $\mathrm{PC}_{10}$ & & 0.0001 & 2.82015 & 5.84941 & 18.80 \\
\hline $\mathrm{PC}_{12}$ & & 0.0001 & 8.46044 & 1.94980 & 26.80 \\
\hline $\mathrm{MC}_{6}$ & \multirow{6}{*}{35} & 0.0025 & 2.96452 & 5.56454 & 4.00 \\
\hline $\mathrm{MC}_{10}$ & & 0.001 & 7.41131 & 2.22582 & 12.00 \\
\hline $\mathrm{MC}_{12}$ & & 0.0005 & 4.44678 & 3.70969 & 20.00 \\
\hline $\mathrm{PC}_{6}$ & & 0.001 & 4.44678 & 3.70969 & 4.00 \\
\hline $\mathrm{PC}_{10}$ & & 0.0005 & 5.92905 & 2.78227 & 13.00 \\
\hline $\mathrm{PC}_{12}$ & & 0.00025 & 2.96452 & 5.56454 & 21.00 \\
\hline $\mathrm{MC}_{6}$ & \multirow{6}{*}{50} & 0.001 & 3.47450 & 4.74779 & 1.00 \\
\hline $\mathrm{MC}_{10}$ & & 0.00025 & 8.06754 & 2.04476 & 6.00 \\
\hline $\mathrm{MC}_{12}$ & & 0.00025 & 2.68918 & 6.13429 & 16.00 \\
\hline $\mathrm{PC}_{6}$ & & 0.00025 & 2.68918 & 6.13429 & 1.00 \\
\hline $\mathrm{PC}_{10}$ & & 0.0001 & 2.68918 & 6.13429 & 9.00 \\
\hline $\mathrm{PC}_{12}$ & & 0.0001 & 8.06754 & 2.04476 & 17.00 \\
\hline
\end{tabular}

Egypt. J. Chem. 55, No. 6 (2012) 
Surface parameters of the prepared surfactants

The surface parameters (effectiveness $\left.\Pi_{\mathrm{CMC}}\right)$, maximum surface excess $\left(\Gamma_{\max }\right)$ and minimum area $\left(\mathrm{A}_{\min }\right)$ of the surfactants were calculated according to Rosen et al. ${ }^{(13)}$ and the data are summarized in Table 3 . These data show the good surface activity of the prepared surfactants and their ability for adsorption at air / water interface. The effectiveness values in Table 3 show an increase with the increase of the alkyl chain moiety of the prepared monomeric and polymeric surfactants which gives indication about the ability of these surfactants towards the adsorption at air / water interface and decrease the surface tension. Also, it is noticed that the effectiveness values of the prepared polymeric surfactants are higher than those of the corresponding monomeric surfactants.

\section{Thermodynamic parameters of micellization}

Table 4 lists the free energies, $\Delta \mathrm{Gmic}$, enthalpies $\Delta \mathrm{Hmic}$, and entorpies, $\Delta$ Smic of micellization for the prepared monomeric and polymeric surfactants in this study. Their parameters were calculated using the following equations according to to Rosen et al. ${ }^{(13)}$.

$$
\begin{gathered}
\Delta \mathrm{G}_{\text {mic }}=2 \mathrm{RT} \ln \mathrm{CMC} \\
\mathrm{d}\left[\Delta \mathrm{G}_{\text {mic }}\right] / \square \Delta \mathrm{T}=-\Delta \mathrm{S}_{\text {mic }} \\
\Delta \mathrm{H}_{\text {mic }}=\Delta \mathrm{G}_{\text {mic }}+\mathrm{T} \Delta \mathrm{S}_{\text {mic }}
\end{gathered}
$$

The $\Delta \mathrm{S}_{\text {mic }}$ values in Table 4 are all positive for the prepared surfactants, indicating an increase in randomness of the system upon transformation of the surfactant molecules into micelles. $\Delta \mathrm{H}_{\text {mic }}$ in Table 4 are significant factors in the process of micellization. The $\Delta \mathrm{H}_{\text {mic }}$ values are positive for the prepared surfactants due to the endothermic solvation associated with micellization process. The data in Table 4 show that the free energies $\Delta \mathrm{G}_{\mathrm{mic}}$ of micellization for the prepared monomeric and polymeric surfactants are always negative values, indicating that, micellization of such surfactants is a spontaneous process. It was noticed that the $\Delta \mathrm{G}_{\text {mic }}$ values of the polymeric surfactants are higher than those of the monomeric surfactants which is related to the more ability of the polymeric surfactants toward the micellization process than the monomeric surfactants.

\section{Thermodynamic parameters of adsorption}

The free energies of activation, $\Delta \mathrm{G}_{\mathrm{ad}}$, enthalpies, $\Delta \mathrm{H}_{\mathrm{ad}}$, and entropies, $\Delta \mathrm{S}$ ad values of adsorption listed in Table 3 were calculated by the following equations according to Rosen et al. ${ }^{(13)}$.

$$
\begin{gathered}
\Delta \mathrm{G}_{\mathrm{ad}}=\Delta \mathrm{G}_{\text {mic }}-\left(6.023 \times 10^{-1} \pi \mathrm{cmc}_{\min }\right) \\
\Delta \mathrm{S}_{\mathrm{ad}}=\mathrm{d} \Delta \mathrm{G}_{\mathrm{ad}} / \Delta \mathrm{T} \\
\Delta \mathrm{H}_{\mathrm{ad}}=\Delta \mathrm{G}_{\mathrm{ad}}+\mathrm{T} \Delta \mathrm{S}_{\mathrm{ad}}
\end{gathered}
$$

Egypt. J. Chem. 55, No. 6 (2012) 
TABLE 4. Thermodynamic parameters of micellization and adsorption for the prepared monomeric surfactant $\left(\mathrm{MC}_{6}, \mathrm{MC}_{10}\right.$ and $\left.\mathrm{MC}_{12}\right)$ and their analogues polymeric surfactants .

\begin{tabular}{|c|c|c|c|c|c|c|c|}
\hline Surfactant & T $\quad\left({ }^{0} \mathrm{C}\right)$ & $\underset{k \mathrm{kJmol}}{\Delta \mathbf{G}_{\text {mic. }}^{0}}$ & $\underset{\mathrm{kJJmol}^{-1} \cdot \mathrm{K}^{-1}}{\Delta \mathbf{S}^{0}}$ & $\underset{\text { kJ.mol }}{\Delta \mathbf{H}^{0}{ }_{\text {mic }}}$ & $\underset{\mathrm{kJ} \cdot \mathrm{mol}}{\Delta \mathbf{G}^{-1}}$ & 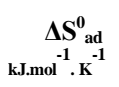 & $\begin{array}{r}\Delta \mathbf{H}_{\text {ad }}^{\mathbf{0}} \\
\mathrm{kJ} \cdot \mathrm{mol}^{-1}\end{array}$ \\
\hline $\mathrm{MC}_{6}$ & & -14.57883 & & & -17.19302 & & \\
\hline $\mathrm{MC}_{10}$ & & -16.80841 & & & -19.19470 & & \\
\hline $\mathrm{MC}_{12}$ & & -18.49503 & & & -24.25965 & & \\
\hline $\mathrm{PC}_{6}$ & & -16.80841 & & & -18.77464 & & \\
\hline $\mathrm{PC}_{10}$ & & -18.49503 & & & -21.64546 & & \\
\hline $\mathrm{PC}_{12}$ & & -20.18164 & & & -29.16372 & & \\
\hline $\mathrm{MC}_{6}$ & & -19.44187 & 0.13169 & 24.00515 & -20.25991 & 0.05408 & -1.34807 \\
\hline $\mathrm{MC}_{10}$ & & -21.21483 & 0.25564 & 60.32353 & -22.62407 & 0.19313 & 39.39439 \\
\hline $\mathrm{MC}_{12}$ & & -21.21483 & 0.25564 & 60.32353 & -28.96565 & 0.36555 & 89.91301 \\
\hline $\mathrm{PC}_{6}$ & & -21.21483 & 0.25564 & 60.32353 & -22.62407 & 0.18082 & 35.78591 \\
\hline $\mathrm{PC}_{10}$ & & -23.55855 & 0.33757 & 84.32868 & -28.13858 & 0.36127 & 88.65884 \\
\hline $\mathrm{PC}_{12}$ & & -23.55855 & 0.33757 & 84.32868 & -26.02472 & 0.32022 & 76.63060 \\
\hline $\mathrm{MC}_{6}$ & & -18.52941 & & 24.00515 & -18.81537 & & \\
\hline $\mathrm{MC}_{10}$ & & -22.24802 & & 60.32353 & -22.98695 & & \\
\hline $\mathrm{MC}_{12}$ & & -22.24802 & & 60.32353 & -28.15951 & & \\
\hline $\mathrm{PC}_{6}$ & & -22.24802 & & 60.32353 & -22.61749 & & \\
\hline $\mathrm{PC}_{10}$ & & -24.70588 & & 84.32868 & -28.03110 & & \\
\hline $\mathrm{PC}_{12}$ & & -24.70588 & & 84.32868 & -26.79954 & & \\
\hline
\end{tabular}

Egypt. J. Chem. 55, No. 6 (2012) 
According to the data given in Table 3 , the $\Delta \mathrm{G}_{\mathrm{ad}}$ values are negative, reflecting to the tendency of adsorption at liquid / air interface for the prepared surfactants. Comparing the data in Table 4 it is noticed that the $\Delta \mathrm{G}_{\mathrm{ad}}$ values of the prepared monomeric and polymeric surfactants are higher than the $\Delta G_{\text {mic }}$ values indicating that the prepared surfactants favored the adsorption at air / water interface more than the micellization process. The $\Delta \mathrm{S}_{\mathrm{ad}}$ values are all positive, this may reflect the greater freedom of motion of the hydrocarbon chains at the planar air / aqueous solution interface compared to that in the relatively cramped interior beneath the convex surface of the micelle. The most $\Delta \mathrm{H}_{\mathrm{ad}}$ values are less than $\Delta \mathrm{H}_{\text {mic }}$, which indicates that less hydrogen bonds between the hydrophilic groups $\left(\mathrm{SO}_{3} \mathrm{Na}\right)$ in the synthesized surfactants and water molecules are broken in the process of adsorption at the air/solution interface than in micellization process.

\section{Conclusion}

- The solubility of the three prepared monomeric and their polymeric surfactants in water is improved by the substitution of different surfactant moieties on the $-\mathrm{OH}$ group of 3-hydroxyaniline as confirmed from the surface and thermodynamic values.

- The thermal stability of the prepared polymeric surfactants is also improved.

- From the X-ray diffraction analysis and electron microscopy it can be concluded that the crystallinity decreases by increasing the alkyl chain length.

\section{References}

1. Sayyah, S.M., Abd El-Salam, H.M. and Azzam, E.M.S., Oxidative chemical polymerization of some 3-alkyloxyanikline surfactant and characterization of the obtained polymer. Inter. J. Polymeric Materials, 55, 1 (2006).

2. Salaneck, W.R., Lundström, I. and Rånby, B., Nobel Symposium in Chemistry: Conjugated polymers and related materials: The interconnection of chemical and electronic structures, Oxford Sci. Oxford (1993)

3. Maria, C.M., Diego, F.A., Natalia, M., Evelina, Claudia, R.R. and Cesar, A.B., Organic chemistry of polyanilines: Tailoring properties to technological applications. The Open Macromolecules Journal, 1, 58 (2008).

4. Sayyah, S.M., Abd El-Khalek, A.A. and Abd El-Salam, H.M., Kinetic studies of the polymerization of substituted aniline in aqueous solutions and characterization of the polymer obtained. J. Polym. Mater. 49, 25 (2001) .

5. Huang, L.M., Wen, T.C. and Gopalan, A., Synthesis and characterization of soluble conducting poly(aniline-co-2, 5-dimethoxyaniline). Mater. Letts. 57, 1765 (2003). 
6. Sayyah, S.M., Abd El-Salam, H.M. and Azzam, E.M.S., Surface activity of monomeric and polymeric (3-alkyloxy aniline) surfactants . Inter. J. Polymeric Materials, 54, 541 (2005).

7. Sayyah, S.M., El-Salam, H.M.A. and Bahgat, A.A., Aqueous oxidative polymerization of 3-methoxyaniline and characterization of its polymer. J. Polym. Mater. 51, 915 (2002).

8. Yue, J., Wang, Z.H., Cromaek, R.K., Epstein, A.J. and MacDiiarmid, A.G., Effect of sulfonic acid group on polyaniline backbone. J. Am. Chem. Soc. 113, 2665 (1991).

9. Genies, E.M. and Noel, P., Novel in-situ conductivity measurement, poly (3methyl thiophene) and an alkoxysulfonated polyaniline. Synth. Met. 55, 4192 (1993).

10. Krister Holmberg, Bo J“onsson, Bengt Kronberg and Bj̈orn Lindman, Surfactants and Polymers in Solution in Aqueous Solution, $2^{\text {nd }}$ ed., John Wiley \& Sons, Chichester (2003) .

11. Holmberg, K., Jonsson, B., Kronberg, B. and Lindman, B., Surfactants and Polymers Solution, $2^{\text {nd }}$ ed., John Wiley \& Sons, Chichester (2003).

12. Rosen, M.J. and Hua. X.Y., Surface concentrations and molecular interactions in binary mixtures of surfactants. J. Colloid and Interface Sci. 86 (1), 164 (1982). 


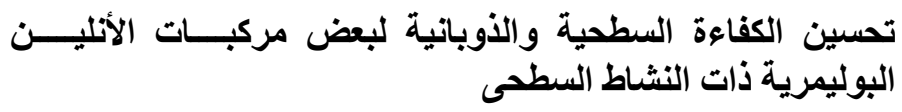

السعيد محمود أحمد صباح ، عيد عزام* ، امجد بهيج خليل و سلامة محمد محمد

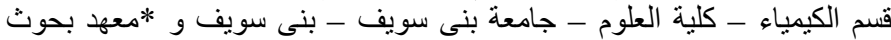

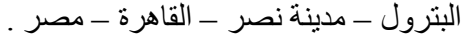

يتضمن هذا البحث طرق تخليق ثلاث منومرات لها خصائص سطحية منميزة وتصلح

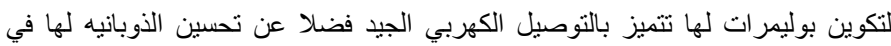

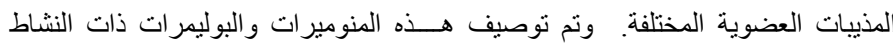

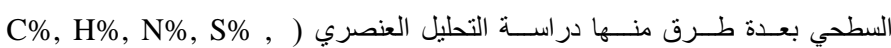
Na\% ,Cl\%

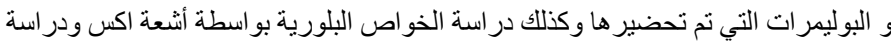

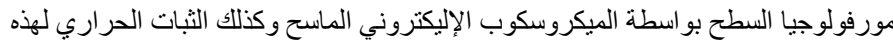

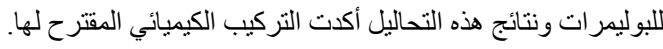

تم دراسة الخواص الفيزيائية لهذه المنومرات و البوليمرات حيث تم دراسة خاصية التوتر السطحي عند درجات حرارة مختلفة و أظهرت النتائج تناقص التوتر السطحي مع الته

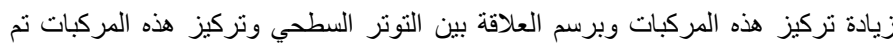

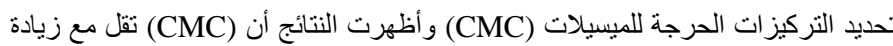

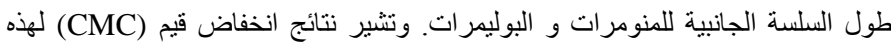
المنومر ات و البوليمر ات إلى تحسن ذوبانها في المحاليل المانئية.

كما تم در اسة فاعلية السطح (

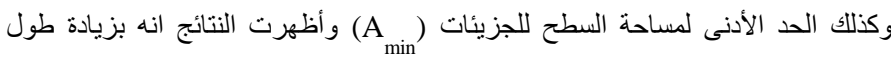

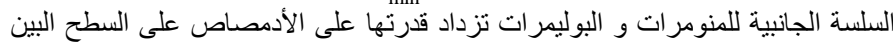

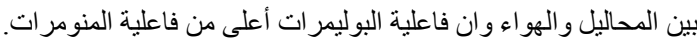

كما تم حساب المعاملات الحرارية للميسيلات $)$

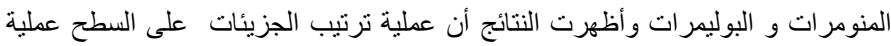

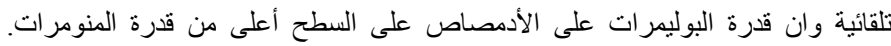

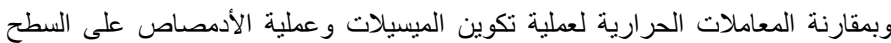

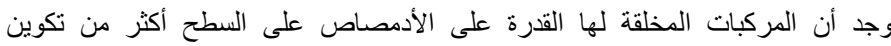
الميسيلات في المحلول. 